\title{
Note
}

\section{In vitro Peroxynitrite Scavenging Activity of Arctic Seaweed Extracts}

\author{
Youngwan Seo ${ }^{1 *}$, Hee-Jung Lee ${ }^{2}$, You Ah Kim ${ }^{1}$, Jung-Im Lee ${ }^{1}$, Ji Hee Kim ${ }^{3}$, \\ Hosung Chung, and Sung-Ho Kang ${ }^{3}$ \\ ${ }^{1}$ Division of Marine Environment and Bioscience \\ Korea Maritime University, Busan 606-791, Korea \\ ${ }^{2}$ Busan Regional Food \& Drug Administration, Test \& Analysis Center \\ Busan 608-829, Korea \\ ${ }^{3}$ Korea Polar Research Institute, KORDI \\ Songdo Techno Park, Incheon 406-840, Korea
}

\begin{abstract}
In this study, antioxidant activities of acetone/dichloromethane and methanol extracts of Arctic seaweeds were investigated. The antioxidant properties of both extracts of arctic seaweed were evaluated using two different peroxynitrite tests, including scavenging power on authentic peroxynitrite and inhibitory activities on peroxynitrite generation from 3-morpholinosydnonimine (SIN-1) producing superoxide anion and nitric oxide simultaneously in vitro. At concentration of $10 \mu \mathrm{g} / \mathrm{m} l$, the acetone/dichloromethane and methanol extracts of Odonthalia dentata exhibited 54.6 and $64.2 \%$ inhibition against peroxynitrite generation from SIN-1 while they exhibited 24.3 and $23.0 \%$ scavenging activities on authentic peroxynitrite, respectively. On the other hand, the acetone/dichloromethane extract of Polysiphonia stricta exhibited $61.8 \%$ inhibition only against the induced peroxynitrite from SIN-1. Furthermore, the crude extracts of Odonthalia dentata and Polysiphonia stricta were fractionated into $n$-hexane, $85 \%$ aq. $\mathrm{MeOH}, n$ - $\mathrm{BuOH}$, and $\mathrm{H}_{2} \mathrm{O}$ fractions, successively, and only $85 \%$ aq. $\mathrm{MeOH}$ fraction exhibited the best inhibition.
\end{abstract}

Key words : Arctic seaweed, peroxynitrite, Odonthalia dentata, Polysiphonia stricta

\section{Introduction}

Peroxynitrite is produced by the reaction of nitric oxide (NO) with superoxide in living organisms. Superoxide anion radical and nitric oxide belong to reactive oxygen species (ROS) and reactive nitrogen species (RNS), respectively (Patel et al. 1999). These activated reactive species are generated continuously via normal physiological processes, and more significantly in pathological conditions. Upon stimulation by inflammation and/or infection, macrophages and neutrophils can be activated to produce large amounts of peroxynitrite, and its overproduction exerts strong deleterious influence on homeostatic regulation of our body (Fang et al. 2002; Grace et al. 1998). Peroxynitrite is a potent oxidant (1,000 times more active than equidose hydrogen peroxide) that is able to oxidize and nitrosylate

\footnotetext{
*Corresponding author. E-mail : ywseo@hhu.ac.kr
}

a large variety of biomolecules. Various toxic effects of peroxynitrite have been described, such as oxidation and nitration of proteins (Virag et al. 2003; Reiter et al. 2002). Therefore, the study of peroxynitrite scavenger and its reaction mechanism might be a valuable tool for preventive therapeutic strategies.

Marine organisms are virtually untapped sources of natural products, many of them are biologically active and structurally unique. The significance of seaweed as a source for biologically active natural products is also well known (Ali et al. 2000). Nevertheless, secondary metabolites that scavenge peroxynitrite anion from marine algae have little been investigated and only a few compounds have been found in marine algae (Chung et al. 2001; Lee et al. 2004; Jung et al. 2006). In our continuous search for novel metabolites from marine resources (Lee ${ }^{\mathrm{a}}$ et al. 2004; Lee $^{b}$ et al. 2004; Seo et al. 2004; Lee and Seo 2006; Jung et al. 2004), we have attempted to characterize the 
antioxidative effects of arctic seaweed extracts.

\section{Materials and Method}

\section{Sample Collection, Extraction, and Fractionation}

The seaweed samples were collected from July to August 2005 at Kongsfjorden in the Svalbard Islands, the Arctic. The taxonomic identifications of seaweed specimens were confirmed by an alga taxonomist, J. H. Kim, at the KOPRI, Korea. Shade-dried seaweed was extracted with a volumetrically equal mixture of acetone and dichloromethane for $24 \mathrm{hr}$ at room temperature. This step was repeated twice. The extracted solution was then evaporated to dryness under vacuum, yielding a dark and sticky residue. The seaweed residue was then extracted once more with methanol, according to the same procedure. Each of the crude extracts was used as experimental material. The prepared samples were then stored in a refrigerator at $20^{\circ} \mathrm{C}$, for later study. Each of combined crude extracts of Odonthalia dentata and Polysiphonia stricta was suspended in $\mathrm{H}_{2} \mathrm{O}$ and then partitioned between $\mathrm{CH}_{2} \mathrm{Cl}_{2}$ and $\mathrm{H}_{2} \mathrm{O}$. The $\mathrm{CH}_{2} \mathrm{Cl}_{2}$ fraction was further partitioned with $n$-hexane and $85 \%$ aqueous $\mathrm{MeOH}$ and then the $\mathrm{H}_{2} \mathrm{O}$ fraction successively fractionated with $n-\mathrm{BuOH}$ and $\mathrm{H}_{2} \mathrm{O}$.

\section{Chemicals}

L-ascorbic acid, DL-penicillamine (DL-2-amino-3mercapto-3-methyl butanoic acid) and 3-morpholinosydnonimine (SIN-1) were purchased from Sigma-Aldrich Chemical Company (St.Louis, MO, USA). The Dihydrorhodamine 123 (DHR 123) and peroxynitrite were of the highest quality commercially available and were purchased from Molecular Probes (Eugene, Oregon, USA), and Cayman (Ann Arbor, MI, USA), respectively.

\section{Measurement of $\mathrm{ONOO}^{-}$Scavenging Activity}

The peroxynitrite $\left(\mathrm{ONOO}^{-}\right)$scavenging ability was measured by monitoring the oxidation of dihydrorhodamine 123 using a modified version of the method of Kooy et al. (1994). The peroxynitrite reacts with DHR 123, causing oxidized DHR 123 to form, and its converted chemical structure is capable of emitting fluorescence. A stock solution of DHR $123(5 \mathrm{mM})$ purged with nitrogen was prepared in advance and stored at $-80^{\circ} \mathrm{C}$. A working solution of DHR 123 (final concentration, $5 \mathrm{M}$ ) was diluted from the stock solution and placed on ice in the dark immediately prior to the measurement. The buffer of $90 \mathrm{mM}$ sodium chloride, $50 \mathrm{mM}$ sodium phosphate $(\mathrm{pH}$ 7.4) and $5 \mathrm{mM}$ potassium chloride with $100 \mathrm{M}$ (f.c.) diethylenetriaminepentaacetic acid (DTPA) was purged with nitrogen and placed on ice before use. The $\mathrm{ONOO}^{-}$ scavenging ability, based on the oxidation of DHR 123 , was determined with a microplate fluorescence spectrophotometer, FL 500 (Bio-Tek instruments, USA) using the wavelengths of $485 \mathrm{~nm}$ and $530 \mathrm{~nm}$ for excitation and emission, respectively, at room temperature. The background and final fluorescent intensities were measured 5 min after treatment with or without SIN-1 (f.c. $10 \mathrm{M}$ ) or authentic $\mathrm{ONOO}^{-}$(f.c. $10 \mathrm{M}$ ) in $0.3 \mathrm{~N}$ sodium hydroxide. The oxidation of DHR 123 due to decomposition of the SIN-1 gradually proceeded whereas the authentic $\mathrm{ONOO}^{-}$rapidly oxidized DHR 123 with the final fluorescent intensity being stable over time. Penicillamine was used as a positive control.

\section{Results and Discussion}

The antioxidant activity of twenty seaweed extracts was determined by the scavenging effect on authentic $\mathrm{ONOO}^{-}$ and inhibitory effect of $\mathrm{ONOO}^{-}$generation from SIN-1, according to the method of Kooy et al. (1994). Two different pathways appear to exist in the peroxynitrite system. One is simply scavenging authentic $\mathrm{ONOO}^{-}$. The other is to scavenge the superoxide anion $\left(\cdot \mathrm{O}_{2}^{-}\right)$and nitric oxide $(\cdot \mathrm{NO})$ generated from SIN-1 and to subsequently inhibit the formation of $\mathrm{ONOO}^{-}$from SIN-1, a generator of peroxynitrite through the reaction between nitric oxide and superoxide anion (Zou et al. 2002). As summarized in Table 1, the antioxidative capabilities of twenty arctic seaweed extracts were compared with penicillamine and L-ascorbic acid.

At $10 \mu \mathrm{g} / \mathrm{m} l$ concentration of acetone/dichloromethane extract, ten seaweed extracts were comparatively effective in their inhibitory activities on SIN-1, which increased in the following order: Chordaria flagelliformis (34.4\%), Devaleraea ramentacea (41.3\%), and Monostroma obscurum (41.3\%), Chorda filum (44.6\%), Phycodrys rubens (45.9\%), Alaria esculenta (46.3\%), Laminaria solidungula (47.8\%), Spongomorpha arcta (50.2\%), Odonthalia dentata (54.6\%), and Polysiphonia stricta (61.8\%). The methanol extracts of the Arctic seaweeds -- except for Odonthalia dentate (64.2\%) and Desmarestia aculeate (46.0\%) -- did not show significant inhibitory activities in this system. On the other hand, crude extracts of seaweed showed little scavenging effect on authentic peroxynitrite; that of only two species, acetone/dichloromethane of Spongomorpha arcta $(26.1 \%)$ and both extracts of Odonthalia dentata (24.3\% and $23.0 \%$ ) were found to be the best among them. 
Table 1. Peroxynitrite inhibitory/scavenging activities of seaweed extracts $(10 \mu \mathrm{g} / \mathrm{m} l)$

\begin{tabular}{|c|c|c|c|c|}
\hline \multirow[b]{2}{*}{ Species $(10 \mathrm{ug} / \mathrm{m} l)$} & \multicolumn{2}{|c|}{ SIN-1 } & \multicolumn{2}{|c|}{ Authentic peroxynitrite } \\
\hline & Acetone $/ \mathrm{CH}_{2} \mathrm{Cl}_{2}$ ext. & MeOH ext. & Acetone $/ \mathrm{CH}_{2} \mathrm{Cl}_{2}$ ext. & MeOH ext. \\
\hline \multicolumn{5}{|l|}{ Green algae } \\
\hline Spongomorpha arcta & 50.2 & 28.0 & 26.0 & 2.7 \\
\hline Monostroma obscurum & 41.3 & 3.0 & 5.5 & - \\
\hline \multicolumn{5}{|l|}{ Brown algae } \\
\hline Alaria esculenta & 46.3 & 34.0 & 12.1 & 10.6 \\
\hline Laminaria digitata & 32.8 & 29.5 & - & - \\
\hline Laminaria saccharina & 25.6 & 16.3 & - & - \\
\hline Desmarestia aculeata & 33.4 & 46.0 & - & - \\
\hline Laminaria solidungula & 47.8 & 29.1 & 8.7 & - \\
\hline Chorda filum & 44.6 & 24.8 & - & 5.0 \\
\hline Fucus distichus ssp edentatus & 32.4 & 19.4 & 7.4 & - \\
\hline Chordaria flagelliformis & 43.4 & 15.5 & 13.0 & - \\
\hline Laminaria sp. 1 & 24.3 & 5.8 & 6.1 & 5.8 \\
\hline Laminaria sp. 2 & 25.4 & 12.3 & 3.3 & 0.6 \\
\hline Laminaria hyperborea & 26.5 & 8.4 & - & - \\
\hline \multicolumn{5}{|l|}{ Red algae } \\
\hline Ptilota seriata & 38.8 & 6.4 & 4.5 & 7.4 \\
\hline Polysiphonia stricta & 61.8 & 32.4 & 3.5 & 17.2 \\
\hline Phycodrys rubens & 45.9 & 20.4 & - & 6.5 \\
\hline Devaleraea ramentacea & 41.3 & 27.4 & - & 1.7 \\
\hline Odonthalia dentata & 54.6 & 64.2 & 24.3 & 23.0 \\
\hline Callophllis cristata & 28.5 & 19.6 & 15.2 & - \\
\hline Palmaria palmata & 21.2 & - & 3.0 & - \\
\hline Penicilamine & 88.2 & & 90.4 & \\
\hline L-ascorbic acid & 93.5 & & 98.1 & \\
\hline
\end{tabular}

Table 2. Effects of solvent fractions from polysiphonia stricta and Odonthalia dentata on peroxynitrite from decomposition of SIN-1 and authentic peroxynitrite $(10 \mu \mathrm{g} / \mathrm{m} l)$

\begin{tabular}{|c|c|c|c|c|c|c|c|c|}
\hline \multirow[b]{2}{*}{ Seaweeds } & \multicolumn{4}{|c|}{$\mathrm{ONOO}^{-}$from decomposition of SIN-1 } & \multicolumn{4}{|c|}{ Authentic peroxynitrite } \\
\hline & $n$-hexane & $\begin{array}{c}\text { 85\% aq. } \\
\text { МeOH }\end{array}$ & n-BuOH & $\mathrm{H}_{2} \mathrm{O}$ & $n$-hexane & $\begin{array}{c}85 \% \text { aq. } \\
\text { МeOH }\end{array}$ & n-BuOH & $\mathbf{H}_{2} \mathbf{O}$ \\
\hline Polysiphonia stricta & 38.8 & 82.1 & 60.2 & 32.0 & 14.7 & 52.9 & 60.7 & 20.2 \\
\hline Odonthalia dentata & 31.3 & 82.9 & 57.7 & 25.6 & 17.4 & 37.8 & 27.0 & - \\
\hline Penicillamine & \multicolumn{4}{|c|}{88.2} & \multicolumn{4}{|c|}{90.4} \\
\hline L-ascorbic acid & \multicolumn{4}{|c|}{93.5} & \multicolumn{4}{|c|}{98.1} \\
\hline
\end{tabular}

On the basis of the above results, these two seaweed extracts which are the most active were fractionated with $n$-hexane, $85 \%$ aq. $\mathrm{MeOH}, n$ - $\mathrm{BuOH}$ and $\mathrm{H}_{2} \mathrm{O}$ and then all fractions were tested on peroxynitrite in vitro (Table 2). The $85 \%$ aq. MeOH fractions of both Odonthalia dentata and Polysiphonia stricta exhibited the best activities for the induced peroxynitrite from SIN-1 and authentic peroxynitrite, thus suggesting these fractions may contain antioxidative components with moderately polar chemical features.

In ${ }^{1} \mathrm{H}$ NMR spectrum of each of their $85 \%$ aq. $\mathrm{MeOH}$ fractions, several signals in the region of $\delta 3.2-4.5$ as well as one strong signal at $\sim \delta 1.3$ showed that compounds which have sugar moieties and long aliphatic chains exist as major components. In addition, a few peaks in downfield region of $\delta 6.4-7.4$ indicated a possibility that 
aromatic compounds, probably phenol derivatives, may exist.

Although secondary metabolites from the red alga Polysiphonia stricta have never been reported, brominated phenols from other species of the genus of Polysiphonia were isolated as secondary metabolites (Pedersen 1978; Aknin et al. 1992; Flodin and Whitfield 2000). In case of the red alga Odonthalia dentata, brominated phenols including lanosol were also isolated and biological activities of the lanosol were investigated (Craigie and Gruenig 1967; Kurata and Taniguchii 1997; DeBusk et al. 2000). Phenol derivatives are well-known as free radical scavengers which play an important role in preventing oxidative damage (Yokozawa et al. 1998). The presence of a hydroxy group in the phenol ring plays an important role in the antioxidant activity in the ONOO systems (RiceEvans et al. 1996; Choi et al. 2002).

The results of this study indicate that Odonthalia dentata and Polysiphonia stricta may be useful as source for the treatment of oxidative damage by reactive nitrogen species, particularly in pathological conditions. To the best of our knowledge, this is the first report on the antioxidative activity of seaweeds collected from the Arctic. However, the components responsible for the antioxidant activity of both seaweed species are currently unclear at this stage. Therefore, it is suggested that further work should be performed on the isolation and identification of the antioxidant components in their active extracts.

\section{Acknowledgements}

This work was supported by Korea Research Foundation (KRF) grant KRF-2006-005-J0050.

\section{References}

Aknin, M., A. Samb, J. Mirailles, V. Costantino, E. Fattorusso, and A. Mangoni. 1992. Polysiphenol, a new brominated 9,10-dihydrophenanthrene from the senegalese red alga polysyphonia ferulacea. Tetrahedron Lett., 33, 555-558.

Ali, M.S., M. Jahangir, M., Saleen, M.K. Pervez, S. Hameed, and V.U. Ahmad. 2000. Metabolites of marine algae collected from Karachi-coasts of arabian sea. Nat. Prod. Sci., 6, 61-65.

Choi, J.S., H.Y. Chung, S.S. Kang, M.J. Jung, J.W. Kim, J.K. No, and H.A. Jung. 2002. The structure-activity relationship of flavonoids as scavengers of peroxynitrite. Phytochem. Res., 16, 232-235.

Chung, H.Y., H.R. Choi, H.J. Park, J.S. Choi, and W.C. Choi. 2001. Peroxynitrite scavenging and cytoprotective activity of 2,3,6-tribromo-4,5-dihydroxybenzyl methyl ether from the marine alga Symphyocladia latiuscula. $J$. Agr. Food Chem., 49, 3614-3621.

Fang, Y.Z., S. Yang, and G. Wu. 2002. Free radicals, antioxidants and Nutrition. Nutrition, 18, 872-879.

Flodin, C. and F.B. Whitfield. 2000. Brominated anisoles and cresols in the red alga Polysiphonia sphaerocarpa. Phytochemistry, 53, 77-80.

Grace, S.C., M.G. Salgo, and W.A. Pryor. 1998. Scavenging of peroxynitrite by a phenolic/peroxidase system prevents oxidative damage to DNA. FEBS Lett., 426, 24-28.

Jung, H.A., H.J. Lee, Y.A. Kim, K.E. Park, J.W. Ahn, B.J. Lee, S.G. Moon, and Y. Seo. 2004. Antioxidant activity of Artemisia capillaris Thunberg. Food Sci. Biotechnol., $13,328-331$.

Jung, H.A., S.K. Hyun, H.R. Kim, and J.S. Choi. 2006. Angiotensin-converting enzyme I inhibitory activity of phlorotannins from Ecklonia stolonifera. Fish. Sci., 72, 1292-1299.

Kooy, N.W., J.A., Royall, H. Ischiropoulos, and J.S. Beckman. 1994. Peroxynitrite-mediated oxidation of dihydrorhodamine 123. Free Radic. Biol. Med., 16, 149156.

Kurata, K. and K. Taniguchii. 1997. Feeding-deterrent bromophenols from Odonthalia corymbifera. Phytochemistry, 45, 485-487.

Lee, H.J., Y.A. Kim, J.W. Ahn, B.J. Lee, S.G. Moon, and Y. Seo. 2004a. Screening of peroxynitrite and DPPH radical scavenging activities from salt marsh plants. Kor. J. Biotechnol. Bioeng., 19, 57-61.

Lee, H.J., K.E. Park, J.S. Yoo, J.W. Ahn, B.J. Lee, and Y. Seo. 2004b. Studies on screening of seaweed extracts for peroxynitrite and DPPH radical scavenging activities. Ocean and Polar Res., 26, 59-64.

Lee, H.-J., K.E. Park, Y.A. Kim, J.W. Ahn, J.S. Yoo, and B.J. Lee. 2004. Peroxynitrite-scavenging constituents from the brown alga Sargassum thunbergii. Biotechnol. Bioprocess Eng., 9, 212-216.

Lee, H.J. and Y. Seo. 2006. Antioxidant properties of Erigeron annuus extract and its three phenolic constituents. Biotechnol. Bioeng., 11, 13-18.

Patel, R.P., J. McAndrew, H. Sellak, C. Roger White, H. Jo, B.A. Freeman, and V.M. Darley-Usmar. 1999. Biological aspects of reactive nitrogen species. Biochim. Biophys. Acta, 1411, 385-400.

Perdersen, M. 1978. Bromochlorophenols and a brominated diphenylmethane in red algae. Phytochemistry, 17, 291293.

Reiter, R.J., D.X. Tan, and S. Burkhardt. 2002. Reactive oxygen and nitrogen species and cellular and organismal decline: amelioration with melatonin. Mech. Aging Dev., 123, 1007-1019.

Rice-Evans, C.A., N.J. Miller, and G. Paganga. 1996. Structure-antioxidant activity relationships of flavonoids and phenolic acids. Free Radical Biol. Med., 20, 933956.

Seo, Y., H.J. Lee, K.E. Park, Y.A. Kim, J.W. Ahn, J.S. 
Yoo, and B.J. Lee. 2004. Peroxynitrite scavenging constituents from the brown Alga Sargassum thunbergii. Biotechnol. Bioeng., 9, 212-216.

Virag, L., E. Szabo, P. Gergely, and C. Szabo. 2003. Peroxynitrite- induced cytotoxicity: mechanism and opportunities for intervention. Toxicol. Lett., 140/141, 113-124.

Yokozawa, T., C.P. Chen, E. Dong, T. Tanaka, G.I. Nonaka, and I. Nishioka. 1998. Study on the inhibitory effect of tannins and flavonoids against the 1,1-diphenyl-2- picrylhydrazyl radicals. Biochem. Pharmacol., 56, 213222.

Zou, Y., A.R. Kim, J.E. Kim, J.S. Choi, and H.Y. Chung. 2002. Peroxynitrite scavenging activity of sinapic acid (3,5-dimethoxyl-4-hydroxycinnamic acid) isolated from Brassica juncea. J. Agric. Food Chem., 50, 5884-5890.

Received Mar. 26, 2007

Revised Jun. 11, 2007

Accepted Jun. 15, 2007 